Swarthmore College

Works

6-1-2018

\title{
Morph-Specific Patterns Of Reproductive Senescence: Connections To Discrete Reproductive Strategies
}

\author{
A. S. Grunst \\ M. L. Grunst \\ Vincent A. Formica \\ Swarthmore College,vformic1@swarthmore.edu \\ M. L. Korody \\ A. M. Betuel
}

See next page for additional authors

Follow this and additional works at: https://works.swarthmore.edu/fac-biology

Part of the Biology Commons, and the Evolution Commons

Let us know how access to these works benefits you

\section{Recommended Citation}

A. S. Grunst, M. L. Grunst, Vincent A. Formica, M. L. Korody, A. M. Betuel, M. Barcelo-Serra, S. Ford, R. A. Gonser, and E. M. Tuttle. (2018). "Morph-Specific Patterns Of Reproductive Senescence: Connections To Discrete Reproductive Strategies". American Naturalist. Volume 191, Issue 6. 744-755. DOI: 10.1086/ 697377

https://works.swarthmore.edu/fac-biology/553

This work is brought to you for free by Swarthmore College Libraries' Works. It has been accepted for inclusion in Biology Faculty Works by an authorized administrator of Works. For more information, please contact myworks@swarthmore.edu. 


\section{Authors}

A. S. Grunst, M. L. Grunst, Vincent A. Formica, M. L. Korody, A. M. Betuel, M. Barcelo-Serra, S. Ford, R. A. Gonser, and E. M. Tuttle 


\title{
Morph-Specific Patterns of Reproductive Senescence: Connections to Discrete Reproductive Strategies
}

\author{
Andrea S. Grunst, ${ }^{1,2, *}$ Melissa L. Grunst, ${ }^{1,2, *}$ Vince A. Formica, ${ }^{3}$ Marisa L. Korody, ${ }^{4}$ \\ Adam M. Betuel, ${ }^{5,6}$ Margarida Barcelo-Serra, ${ }^{1,5}$ Sarah Ford, ${ }^{1}$ Rusty A. Gonser, ${ }^{1,5, \dagger}$ \\ and Elaina M. Tuttle ${ }^{1,5}$
}

1. Center for Genomic Advocacy, Indiana State University, Terre Haute, Indiana 47809; 2. Department of Biology, Behavioural Ecology and Ecophysiology Group, University of Antwerp, 2610 Wilrijk, Belgium; 3. Department of Biology, Swarthmore College, 500 College Avenue, Swarthmore, Pennsylvania 19081; 4. San Diego Zoo, Institute for Conservation Research, San Diego, California 92101; 5. Department of Biology, Indiana State University, Terre Haute, Indiana 47809; 6. Atlanta Audubon Society, Atlanta, Georgia 30342

Submitted June 23, 2017; Accepted November 21, 2017; Electronically published April 3, 2018

Dryad data: http://dx.doi.org/10.5061/dryad.vj5pn.

\begin{abstract}
A BSTRACT: How reproductive strategies contribute to patterns of senescence in natural populations remains contentious. We studied reproductive senescence in the dimorphic white-throated sparrow, an excellent species for exploring this issue. Within both sexes the morphs use distinct reproductive strategies, and disassortative pairing by morph results in pair types with distinct parental systems. White morph birds are more colorful and aggressive than tan counterparts, and white males compete for extrapair matings, whereas tan males are more parental. Tan males and white females share parental care equally, whereas white males provide little parental support to $\tan$ females. We found morph-specific patterns of reproductive senescence in both sexes. White males exhibited greater reproductive senescence than $\tan$ males. This result likely reflects the difficulty of sustaining a highly competitive reproductive strategy as aging progresses rather than high physiological costs of competitiveness, since white males were also long-lived. Moreover, morph was not consistently related to reproductive senescence across the sexes, arguing against especially high costs of the traits associated with white morph identity. Rather, tan females exhibited earlier reproductive senescence than white females and were short-lived, perhaps reflecting the challenges of unsupported motherhood. Results underscore the importance of social dynamics in determining patterns of reproductive senescence.
\end{abstract}

Keywords: senescence, reproductive strategies, parental care, genetic polymorphism, life history.

\footnotetext{
* These authors contributed equally to this article.

† Corresponding author; e-mail: rusty.gonser@indstate.edu.

ORCIDs: A. Grunst, http://orcid.org/0000-0001-5705-9845; M. Grunst, http://orcid.org/0000-0002-3425-4020; Formica, http://orcid.org/0000-0002 -9709-5522; Barcelo-Serra, http://orcid.org/0000-0002-2752-0896; Gonser, http:// orcid.org/0000-0001-5612-246X.

Am. Nat. 2018. Vol. 191, pp 744-755. (C) 2018 by The University of Chicago. 0003-0147/2018/19106-57793\$15.00. All rights reserved.

DOI: $10.1086 / 697377$
}

\section{Introduction}

Senescence, or the gradual deterioration of performance with age, places critical limits on lifetime fitness and has been increasingly documented in nonhuman populations. A recent review identified 340 studies from 175 species that provide evidence for senescence in free-living populations (Nussey et al. 2013). However, quantifying senescence requires tracking marked individuals over long periods of time and determining reproductive success across the life span and thus remains challenging in the field (Nussey et al. 2008; Bouwhuis et al. 2009, 2012). Due to practical difficulties, work on mechanisms of senescence remains dominated by laboratory-based studies. These studies yield incomplete conclusions about patterns of senescence and underlying causal factors, due to the absence of natural social and environmental challenges (Monaghan et al. 2008; Briga and Verhulst 2015).

Life history-based theories predict that reproductive strategies and behavioral traits are critically connected to rates of senescence (Williams 1957; Kirkwood 1977; Nussey et al. 2013). Individuals who invest intensely in reproduction may suffer a "cost of reproduction," jeopardizing somatic maintenance and accelerating system-wide senescence, as manifest by deterioration of body condition, performance, and survivorship with age. For instance, experimentally increasing parental effort through brood size manipulations can increase rates of molecular aging as indicated by telomere dynamics (Reichert et al. 2014) and accelerate actuarial senescence, or the increase in mortality rate with age (Boonekamp et al. 2014). Costs of reproduction may also affect rates of reproductive senescence, or the decline in reproductive performance with age. For example, male houbara buzzards (Chlamydotis undulata) who invest more into extravagant sexual 
displays exhibit faster rates of senescence in sperm quality (Preston et al. 2011), and female red deer with higher earlylife fecundity show faster senescent declines in maternal performance traits (Nussey et al. 2006).

A common conception is that the competitive reproductive strategy of males is more costly than the more parental strategy of females, promoting a "live fast die young" strategy and higher rates of senescence (Bonduriansky et al. 2008). However, empirical data lend equivocal support to this hypothesis (Lemaitre and Gaillard 2013), with some studies suggesting that parental care is more costly than investment into sexually selected competitive traits or displays (Owens and Bennett 1994). Thus, the relative costs and lifehistory implications of competition for mates versus parental care remains an outstanding question (Liker and Székely 2005; Tidiére et al. 2015).

Furthermore, system-wide senescence and reproductive senescence are commonly predicted to occur in concert in response to life-history trade-offs, such as costs of reproduction. However, the degree to which reproductive strategies involve competition versus cooperation may shape patterns of reproductive senescence, potentially independent of the system-wide costs of different strategies. This is because more competitive strategies may be harder to maintain as body condition declines. For instance, faster senescence in polygynous males compared to females could reflect high physiological costs of competitive reproductive strategies and associated sexually selected traits (Bonduriansky et al. 2008; Nussey et al. 2009; Beirne et al. 2015). However, this pattern could also arise because successful competition is not possible for aging males, lowering reproductive success in old age and potentially feeding back to weaken selection for late-life performance (Graves 2007). In contrast, cooperative interactions, such as sharing parental duties, may dampen costs of reproduction (Cram et al. 2015) while also making sustained performance more feasible in aging individuals (Sharp and Clutton-Brock 2010).

Our objective was to examine rates of reproductive senescence and life span in a system that exhibits a welldocumented polymorphism in competitive and parental reproductive strategies. We studied patterns of reproductive senescence in the polymorphic white-throated sparrow (Zonotrichia albicollis) using a long-term data set spanning 18 years. White-throated sparrows provide an excellent system for investigating the relationship between reproductive strategies, social dynamics, and patterns of senescence due to the presence of morph-specific reproductive strategies and a unique social structure (Tuttle 2003). Birds of both sexes occur in two alternative morphs, the white morph and tan morph. Morph is genetically determined by a complex rearrangement on chromosome 2, with white birds heterozygous for the rearrangement and tan birds homozygous, lacking the rearrangement (Thorneycroft 1966; Tuttle et al. 2016). Gene variants within the rearrangement are divergent and function as a coadapted supergene to alter multiple aspects of physiology and behavior (Tuttle et al. 2016). White males have higher testosterone and corticosterone concentrations during breeding than tan males, which may mediate differences in behavior including higher territorial aggression, singing, and extrapair copulation (Kopachena and Falls 1993a; Tuttle 2003; Maney et al. 2005; Swett and Breuner 2009; Horton and Holberton 2010). In contrast, tan males invest more into mate-guarding and parental behavior. In parallel to males, white females sing and engage in territorial aggression, whereas tan females do not sing and are less aggressive. White-throated sparrows pair disassortatively by morph, seemingly because the rearrangement is deleterious in homozygotes and due to behavioral incompatibilities within same-morph pairs (Tuttle et al. 2016). The two alternative pair types, $\mathrm{W} \times \mathrm{T}$ and $\mathrm{T} \times \mathrm{W}$ (male morph appears first), display distinct parental systems. In $\mathrm{W} \times \mathrm{T}$ pairs, parental care is female biased, with white males contributing little. In $\mathrm{T} \times \mathrm{W}$ pairs, males and females share parental duties more equally (Knapton and Falls 1983; Kopachena and Falls 1993b, 1993c; Tuttle 2003; Falls and Kopachena 2010).

In formulating predictions regarding how reproductive strategy and social dynamics influence reproductive senescence in the white-throated sparrow, we recognized that a bidirectional relationship may exist between reproductive strategy and reproductive senescence. First, we generated two alternative predictions based on the concept that energyintensive strategies potentially accelerate senescence systemwide and in turn cause reproductive senescence. In line with theory proposing a central role for sexual selection and competitive behaviors in accelerating senescence (Clutton-Brock and Isvaran 2007; Bonduriansky et al. 2008; Tidiére et al. 2015), white males could experience higher costs of reproduction and faster senescence (system-wide) than tan males because they compete more intensely for mates, as evidenced by higher song rates, aggression, and promiscuity. If competitive behavior drives faster senescence, one would also predict faster senescence in white females due to costs of similar, morph-linked behaviors, including aggressiveness and song production (Vercken et al. 2007). On the other hand, given high costs of parental behavior, tan males and females might senesce faster than white morph counterparts. Costs of parental care are expected to be particularly high in tan females, since they receive little parental support. Second, we also reasoned that the highly competitive reproductive strategy of white males and the unsupported parental effort of tan females might be hard to sustain as system-wide senescence proceeds. Thus, the members of the less cooperative pair type might both be more susceptible to reproductive senescence, even if system-wide senescence occurs at equivalent rates regardless of reproductive strategy. 


\section{Methods \\ Population Monitoring}

Our data derive from a long-term study of white-throated sparrows breeding at the Cranberry Lake Biological Station (State University of New York, College of Environmental Science and Forestry; $44^{\circ} 15^{\prime} \mathrm{N}, 74^{\circ} 48^{\prime} \mathrm{W}$ ) in the Adirondack region of New York. The data set on reproductive success and survivorship spans 18 years (1998-2015) and includes 145 white males, 128 tan males, 100 white females, and 118 tan females.

White-throated sparrows at our study site are banded with Fish and Wildlife bands bearing unique identification numbers and color band combinations that allow visual identification in the field (Master Banding Permit 22296). In addition, all nestlings are uniquely banded and color banded at day 6 of age to allow for monitoring of recruits throughout their lives. Blood samples are taken at the time of banding ( $\sim 80 \mu \mathrm{L}$ for nestlings and $\sim 200 \mu \mathrm{L}$ for adults) for later genetic work. We store hematocrit in lysis buffer at $4^{\circ} \mathrm{C}$ until use (Longmire et al. 1992). For this analysis, unbanded adults on the central study site were assumed to be young breeders ( 1 year old), since the majority ( 90\%) of birds on central territories are banded each year and adults are philopatric. This assumption introduces a degree of error to initial ages but should not affect the longitudinal analysis (within individuals).

White-throated sparrows at Cranberry Lake establish territories in bogs and glades and along habitat edges of forests, streams, and ponds. Territories are located in similar areas each year, facilitating population monitoring. Each year, we survey the population to determine the occupants of each territory and between-year survivorship. Whitethroated sparrows can fledge two clutches per year and repeatedly renest following nest depredation. We use systematic search and behavioral observations across the season to identify all nesting attempts. Most nests are found during building, laying, or incubation, allowing for determination of clutch sizes and hatching rates.

We visit nests every other day to monitor the progression of the nesting cycle and nest depredation. When nestlings are banded on day 6 , we place Thermochron iButtons in nests. We do not revisit the nest until after the nest should have fledged, on day 9 or 10 . We consider nests depredated if temperature profiles from iButtons indicate that the nest was empty before day 9 and parents are not seen feeding fledglings. We consider nests successful if data indicate that nestlings fledged on approximately day 9 and parents are observed with fledglings.

We determine the sex of adults at capture by the presence of a brood patch or cloacal protuberance and confirm sex through behavioral observations. We assess the morph of adults using the visual criteria set forth by Lowther (1961),
Piper and Wiley (1989), and Tuttle (1993, 2003). We also use genetic methods to confirm the sex (Griffiths et al. 1998) and morph (Michopoulos et al. 2007; Romanov et al. 2009) of adults and to sex and morph nestlings.

\section{Genetic Paternity Analyses}

To determine cuckoldry levels, extrapair paternity, and the actual reproductive success of males, we employ genetic paternity analysis. We extract DNA from blood samples using the DNA IQ magnetic extraction system (Promega, Madison, WI) or the Qiagen DNeasy extraction kit. We conduct paternity analysis using five to eight microsatellite loci: Gf01 and Gf12 (Petren 1998), MME1 (Jeffery et al. 2001), Dp $\mu 01$ and $\mathrm{Dp} \mu 03$ (Dawson et al. 1997), and Zole_C02, Zole_C07, and Zole_H02 (Poesel et al. 2009). Procedural details are described in Formica and Tuttle (2009). For this study, we determined the actual reproductive success of males by adjusting apparent reproductive success for the occurrence of extrapair offspring. Females were assigned as the genetic mother of all nestlings in their nests. We did not encounter cases in which female and offspring alleles mismatched, except due to binning errors, and rates of intraspecific brood parasitism are low (Tuttle 2003). Out of 1,536 nestlings genotyped, 254 (16.5\%) were extrapair offspring. We were able to assign only 127 (50.0\%) of the extrapair offspring to a social father, likely due to the presence of unbanded males on the boundaries of our study site. Thus, our estimates of reproductive success underestimate the reproductive success of white males, who are cuckolded and pursue extrapair mating at high rates (Tuttle 2003). This should not bias our results regarding patterns of reproductive senescence.

\section{Statistics}

We performed statistical analyses in $\mathrm{R}$, version 2.15.2 ( $\mathrm{R}$ Development Core Team 2012). To analyze the relationship between annual reproductive success and individual age, we employed generalized linear mixed-effects models (GLMMs) with a Poisson distribution using $\mathrm{R}$ package lme4 (Bates et al. 2012). Significance levels were determined using Wald $Z$-tests, as recommended for generalized linear models with Poisson error structure in the absence of overdispersion (Bolker et al. 2009). We performed analyses in males and females separately, because breeding males and females are paired in nonconstant combinations across years and thus cannot be treated as independent data points. Moreover, we were interested in testing for morph differences in senescence, and conducting separate models within the sexes was the simplest way to achieve this objective. We included year and individual identity as random effects to account for variation in breed- 
ing conditions between seasons and for multiple measurements on the same individual in different years. We additionally retained an observation-level random effect to control for overdispersion (Harrison 2014). The observation-level random effect effectively eliminated overdispersion in this model and elsewhere where applied, as assessed by the overdispersion function authored by Ben Bolker and available online (https://bbolker.github.io/mixedmodels-misc/glmmFAQ .html). We tested linear and quadratic effects of age and also included morph, longevity, and a binary term to indicate final breeding attempt $(1,0 ; 1=$ final breeding attempt, $0=$ otherwise) in the model as fixed effects. We included twoway interactions between morph and other parameters (age, age $^{2}$ [quadratic term], longevity, final breeding attempt) in the initial model. The quadratic term models the potential for nonlinear changes in reproductive success with age. Including longevity in the model controls for selective disappearance of low-quality individuals, which could otherwise obscure longitudinal (within-individual) changes in reproductive performance with age. The final breeding attempt term tests for terminal effects on reproductive performance. Negative terminal effects might arise if individuals in their last breeding season manifest pathologies that subsequently result in mortality, whereas positive terminal effects could occur if individuals with low residual reproductive value invest more into reproduction (Bouwhius et al. 2009; Zhang et al. 2015). We centered continuous variables to alleviate problems with multicollinearity (particularly between age and age $^{2}$ ) and facilitate interpretation of main effects when also including interaction terms (Schielzeth 2010).

Within males, we assessed whether levels of cuckoldry change with age using GLMMs with a binomial distribution (R package lme4; Bates et al. 2012). We used the number of extrapair nestlings as the dependent variable and total number of nestlings as the binomial denominator. We investigated how male success at obtaining extrapair paternity varied with age using a GLMM with a Poisson distribution. We conducted this model within white males only because tan males rarely obtain extrapair paternity (Tuttle 2003). Within females and males, we tested how clutch size and hatching success change with age. For the clutch size model, we used a GLMM with a Poisson distribution. For the hatching success model, we used a binomial GLMM with number of unhatched eggs as the dependent variable and total number of eggs as the binomial denominator. The hatching success and clutch size models included clutch number as a fixed effect and clutch ID as an additional random effect. Otherwise, we used the same random and fixed effects as above.

We also compared annual and lifetime reproductive success and longevity between the sex-morph classes. To assess differences in annual reproductive success we used a GLMM with a Poisson distribution with sex-morph type as the fixed effect and individual, year, and observation as random effects. We compared lifetime reproductive success of the sex-morph classes using GLMMs with a Poisson distribution and first breeding year as a random effect. To assess differences in longevity we used pairwise Wilcoxon tests with a Holm correction for multiple comparisons.

We reduced all models by sequentially removing predictor variables with the highest $P$ value, until all predictor variables were significant (or near significant) at the $\alpha=$ 0.05 level. Model reduction may increase the probability of type I error. Thus, some advocate for presentation of full models (Forstmeier and Schielzeth 2011). However, parameter estimates can be unstable in full models, and our conclusions would not be qualitatively altered if presenting full models. For these reasons and for conciseness, we present simplified models that do not contain nonsignificant terms.

\section{Results \\ Age and Reproductive Performance}

In both males and females, reproductive success varied with age in a morph-specific fashion. In males, there was a significant negative interaction between age $\mathrm{e}^{2}$ and morph (table 1, pt. A). This interaction reflected a negative quadratic effect of male age on reproductive success within white males (table 1, pt. B; fig. 1a) but not tan males. In white males, reproductive success first increased slightly with age and then declined (fig. 1a). In tan males, the effect of age on reproductive success was linear and positive (table 1, pt. C; fig. 1a). The model predicting reproductive success in males also contained a positive interaction between age and whether it was an individual's last breeding season (table 1, pt. A). This interaction reflected greater negative terminal effects in older birds and was significant only within white males (table 1, pt. B). Tan morph males had higher annual reproductive success than white morph males (table 1, pt. A; fig. $1 a$ ). There was no relationship between male longevity and annual reproductive success $(\beta=0.093 \pm 0.105, Z=$ $0.883, P=.377)$.

In females, there was a significant positive interaction between age and morph and negative interaction between age $^{2}$ and morph (table 2, pt. A). These interactions reflected different linear and quadratic effects of age on reproductive success in white and tan females. As in white males, age had a negative quadratic effect on the reproductive success of white females, with success first increasing with age and then declining (table 2, pt. B; fig. 1b). Conversely, there was a positive quadratic effect of age on the reproductive success of tan females, suggesting large early declines in reproductive success followed by lower rates of decline (table 2, pt. C; 
Table 1: Poisson generalized linear mixed-effects models predicting reproductive success from age and morph in dimorphic whitethroated sparrow males (A), more polygamous and aggressive white males (B), and more paternal tan males (C)

\begin{tabular}{|c|c|c|c|}
\hline A. Males & Estimate $(\beta \pm \mathrm{SE})$ & $Z$ & $P>|Z|$ \\
\hline Intercept & $.730 \pm .080$ & 9.148 & $<.001$ \\
\hline Age & $.231 \pm .075$ & 3.094 & .002 \\
\hline $\mathrm{Age}^{2}$ & $-.182 \pm .041$ & -4.485 & $<.001$ \\
\hline Morph $^{\mathrm{a}}$ & $-.100 \pm .058$ & -1.731 & .083 \\
\hline Last year & $-.122 \pm .093$ & -1.305 & .192 \\
\hline Age $\times$ morph $^{\mathrm{a}}$ & $.018 \pm .064$ & .284 & .776 \\
\hline Age $^{2} \times$ morph $^{\mathrm{a}}$ & $-.099 \pm .039$ & -2.491 & .013 \\
\hline Age $\times$ last year & $.208 \pm .096$ & 2.171 & .0299 \\
\hline Random effects & Variance & $\mathrm{SD}$ & $N$ \\
\hline Observation & .563 & .750 & 607 \\
\hline Individual & .025 & .159 & 277 \\
\hline Year & .021 & .146 & 18 \\
\hline B. White males & Estimate $(\beta \pm \mathrm{SE})$ & $Z$ & $P>|Z|$ \\
\hline Intercept & $.609 \pm .104$ & 5.860 & $<.001$ \\
\hline Age & $.242 \pm .111$ & 2.178 & .029 \\
\hline $\mathrm{Age}^{2}$ & $-.298 \pm .061$ & -4.854 & $<.001$ \\
\hline Last year & $-.244 \pm .147$ & -1.657 & .098 \\
\hline Age $\times$ last year & $.306 \pm .145$ & 2.107 & .035 \\
\hline Random effects & Variance & $\mathrm{SD}$ & $N$ \\
\hline Observation & .842 & .918 & 341 \\
\hline Individual & $<.001$ & $<.001$ & 147 \\
\hline Year & $<.001$ & .023 & 18 \\
\hline C. Tan males & Estimate $(\beta \pm \mathrm{SE})$ & $Z$ & $P>|Z|$ \\
\hline Intercept & $.782 \pm .082$ & 9.508 & $<.001$ \\
\hline Age & $.215 \pm .063$ & 3.381 & $<.001$ \\
\hline Random effects & Variance & $\mathrm{SD}$ & $N$ \\
\hline Observation & .380 & .617 & 267 \\
\hline Individual & .035 & .188 & 130 \\
\hline Year & .029 & .172 & 18 \\
\hline
\end{tabular}

${ }^{a}$ White relative to tan morph.

fig. $1 b$ ). There was also evidence of a negative terminal effect on reproductive success in females (table 2, pt. A). Within morphs, this effect was significant only in tan females (table 2, pt. C). White females had higher annual reproductive success than tan females (table 2, pt. A). As in males, female longevity was unrelated to annual reproductive success $(\beta=-0.034 \pm 0.087, Z=-0.389, P=.698)$.

\section{Paternity Retention and Extrapair Paternity}

Retention of paternity varied with age in a morph-specific fashion, as reflected by a negative interaction between male age and morph (table 3, pt. A). White males had lower paternity retention than tan males (table 3, pt. A). Within the white morph, there was a linear decline in paternity retention with age (table 3, pt. B; fig. 2a), indicating that older males were cuckolded more frequently than younger individuals. In contrast, paternity retention was relatively stable or even slightly increased across age classes within the tan morph (table 3, pt. C; fig. $2 b$ ). Paternity retention was not related to male longevity $(\beta=0.239 \pm 0.500, Z=0.479$, $P=.632$ ) or whether it was an individual's last breeding season $(\beta=0.171 \pm 0.675, Z=0.255, P=.799)$, and associated interaction terms were also nonsignificant $(P>.10$ in all cases).

Within white males, success at obtaining extrapair paternity first increased with age and then declined (fig. 3), as indicated by a negative quadratic relationship between extrapair paternity and age $(\beta=-0.664 \pm 0.191, Z=-3.465$, $P<.001)$. The main effect of age on extrapair paternity was positive $(\beta=1.125 \pm 0.286, Z=3.92, P<.001)$.

\section{Clutch Size and Hatching Success}

Hatching success tended to relate to female age in a morphspecific fashion (table 4, pt. A), as reflected by a marginally nonsignificant positive interaction between morph and age. There was a weak, negative quadratic effect of age on hatching success in white females (table 4, pt. B; fig. $4 b$ ). Indeed, the overall negative quadratic relationship between hatching success and age (table 4, pt. A) seemed to be driven by white females. As tan females aged, there was a strong linear decline in hatching success (table 4, pt. C; fig. 4b), with no quadratic component apparent. Female longevity and terminal effects had no influence on hatching success $(P>.50)$. Male age, longevity, and terminal effects were all unrelated to hatching success. Clutch size was unrelated to any age-related parameter $(P>.10$ for simple and quadratic effects of age, longevity, and terminal effects, as well as interaction terms).

\section{Variation in Reproductive Success and Longevity}

Annual reproductive success ranged from 0 to 9 and was lower in white males than in all other sex-morph classes (GLMM: $P<.001$ in all cases, $n=1,016$ observations, 491 individuals, 18 years). White females had higher annual reproductive success than white males $(\beta=0.253 \pm 0.089$, $Z=2.844, P=.004)$, whereas other pairwise comparisons were nonsignificant $(P>.10)$. Annual reproductive success had a mean \pm SE of $2.865 \pm 0.148$ in tan females, $2.586 \pm$ 0.141 in tan males, $3.186 \pm 0.163$ in white females, and $1.754 \pm 0.111$ in white males.

Lifetime reproductive success ranged from 0 to $33(n=$ 375; 101 tan females, 89 tan males, 81 white females, 104 white males, 17 years), and tan females had lower life- 

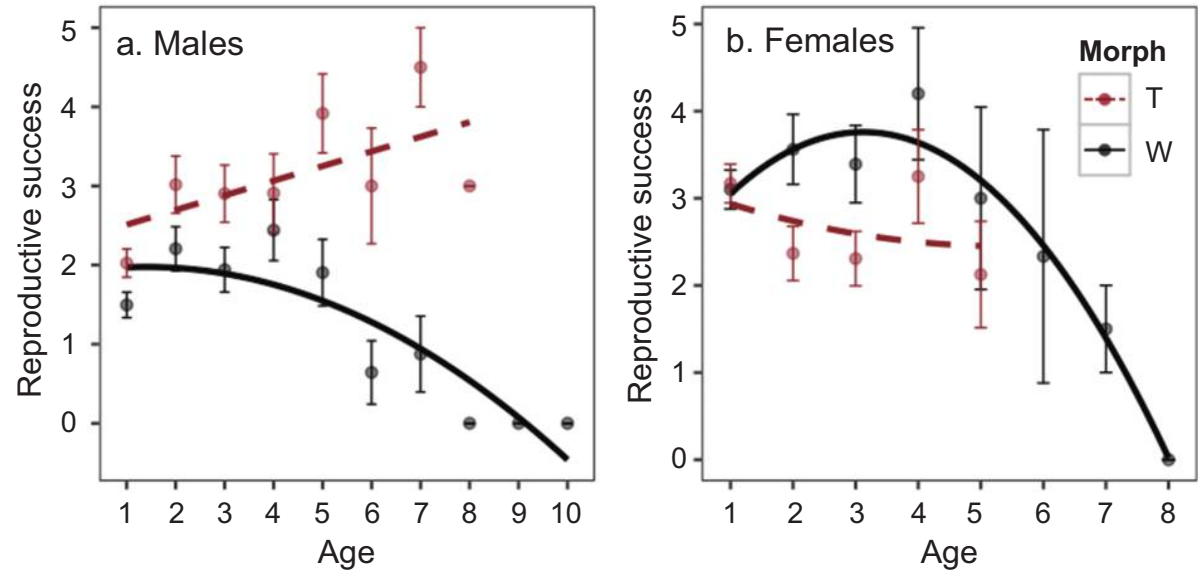

Figure 1: Relationship between reproductive success and age in dimorphic white-throated sparrow males $(a)$ and females $(b)$. In this species, white morph males are more polygamous and aggressive than tan counterparts, which invest more in paternal care. White morph females are more aggressive and receive more paternal support than tan females. Plotted relationships use raw data and quadratic functions in all groups except for tan morph males, in which a linear model best fit the data. Bars denote standard error within age classes.

time reproductive success than tan males (GLMM: $\beta=$ $0.311 \pm 0.063, Z=4.942, P<.001)$, white females $(\beta=$ $0.272 \pm 0.064, Z=4.236, P<.001)$, and white males $(\beta=0.126 \pm 0.063, Z=2.011, P=.044)$. The lifetime reproductive success of tan males was higher than that of white males $(\beta=0.182 \pm 0.061, Z=2.985, P=.003)$ but similar to that of white females $(\beta=-0.031 \pm 0.063$, $Z=-0.496, P=.620)$. White females had higher lifetime reproductive success than white males $(\beta=0.135 \pm 0.063$, $Z=2.149, P=.032$ ). Lifetime reproductive success had a mean \pm SE of $4.842 \pm 0.424$ in tan females, $6.517 \pm$ 0.698 in $\tan$ males, $6.346 \pm 0.590$ in white females, and $5.635 \pm 0.526$ in white males. As stated above, the reproductive success of white males is underestimated due to failure to assign genetic paternity to all extrapair nestlings.

Longevity ranged from 0 to 10 and was higher in white males than in tan females (pairwise Wilcoxon test, $P=.02$ ). Longevity did not differ between other sex-morph classes $(P \geq .30$ in all cases). Longevity had a mean of $2.702 \pm$ 0.102 in tan females, $3.222 \pm 0.107$ in tan males, $3.105 \pm$ 0.147 in white females, and $3.935 \pm 0.116$ in white males.

\section{Discussion}

We demonstrate morph-specific patterns of reproductive senescence in a species with genetically determined alternative reproductive strategies. Morph-specific relationships between age and reproductive performance were present in whitethroated sparrows of both sexes and are likely related to morph differences in aggressive behavior and reproductive strategy. Morph-specific reproductive and behavioral strategies could entail different physiological costs, explaining dif- ferences in reproductive senescence. Alternatively, certain reproductive strategies could be more difficult to sustain given age-related declines in body condition and physiological systems. Below we discuss these two contingencies and what our results suggest regarding the relative costs and life-history outcomes of intrasexual competition versus parental care.

Given high physiological costs of intrasexual competition, we predicted faster reproductive senescence in white than in tan birds. In agreement with this prediction, the reproductive success of white males was stable or increased slightly at young ages and declined thereafter (fig. $1 a$ ), whereas the success of tan males linearly increased with age, perhaps due to reproductive experience (Forslund and Pärt 1995; Martin 1995; Préault et al. 2005; fig. 1b). Older white males exhibited declines in paternity retention and extrapair paternity that contributed to reproductive senescence. High physiological costs of reproduction in white males could promote senescence in reproductive performance traits, including sexual display, sperm quality, and competitive ability (Møller et al. 2009; Velando et al. 2011; Noguera et al. 2012; RiveraGutierrez et al. 2012; Lemaître et al. 2014; Preston et al. 2015). Indeed, compared to tan males, white males exhibit higher levels of aggression (Kopachena and Falls 1993a; Tuttle 2003; Maney et al. 2005), testosterone (Maney et al. 2005; Swett and Breuner 2009), and sexual display, which all may increase physiological costs, for instance, by causing oxidative stress and reducing immunocompetence (Torres and Velando 2007; Peron et al. 2010; Preston et al. 2011; Noguera et al. 2012). Testosterone has been specifically proposed to mediate a trade-off between aggression, sexual attractiveness, and immune function (immunocompetence handicap hypothesis; Folstad and Karter 1992). High testosterone con- 
Table 2: Poisson generalized linear mixed-effects models predicting reproductive success from age and morph in dimorphic whitethroated sparrow females (A), more aggressive white females (B), and more parental tan females $(\mathrm{C})$

\begin{tabular}{|c|c|c|c|}
\hline A. Females & Estimate $(\beta \pm \mathrm{SE})$ & $Z$ & $P>|Z|$ \\
\hline Intercept & $1.070 \pm .073$ & 14.602 & $<.001$ \\
\hline Age & $-.025 \pm .058$ & -.430 & .667 \\
\hline $\mathrm{Age}^{2}$ & $.011 \pm .038$ & .279 & .780 \\
\hline Morph $^{\mathrm{a}}$ & $.157 \pm .051$ & 3.073 & .002 \\
\hline Last year & $-.195 \pm .074$ & -2.632 & .009 \\
\hline Age $\times$ morph $^{a}$ & $.142 \pm .057$ & 2.467 & .014 \\
\hline Age $^{2} \times$ morph $^{\mathrm{a}}$ & $-.110 \pm .038$ & -2.875 & .004 \\
\hline Random effects & Variance & $\mathrm{SD}$ & $N$ \\
\hline Observation & .179 & .423 & 418 \\
\hline Individual & .015 & .124 & 224 \\
\hline Year & .028 & .169 & 18 \\
\hline B. White females & Estimate $(\beta \pm \mathrm{SE})$ & $Z$ & $P>|Z|$ \\
\hline Intercept & $1.173 \pm .067$ & 17.589 & $<.001$ \\
\hline Age & $.141 \pm .079$ & 1.771 & .077 \\
\hline $\mathrm{Age}^{2}$ & $-.103 \pm .036$ & -2.836 & .004 \\
\hline Random effects & Variance & SD & $N$ \\
\hline Observation & .218 & .467 & 201 \\
\hline Individual & $<.001$ & $<.001$ & 102 \\
\hline Year & .007 & .083 & 18 \\
\hline C. Tan females & Estimate $(\beta \pm \mathrm{SE})$ & $Z$ & $P>|Z|$ \\
\hline Intercept & $.976 \pm .106$ & 9.162 & $<.001$ \\
\hline Age & $-.181 \pm .084$ & -2.134 & .033 \\
\hline Age $^{2}$ & $.133 \pm .069$ & 1.939 & .052 \\
\hline Last year & $-.326 \pm .107$ & -3.057 & .002 \\
\hline Random effects & Variance & $\mathrm{SD}$ & $N$ \\
\hline Observation & .132 & .363 & 218 \\
\hline Individual & .059 & .242 & 122 \\
\hline Year & .033 & .181 & 17 \\
\hline
\end{tabular}

${ }^{a}$ White relative to tan morph.

centrations could suppress immunity, resulting in cumulative damage and mediating senescence (Mougeot et al. 2004; Alonso-Alvarez et al. 2007; Mills et al. 2009).

In addition, morph differences in responsiveness to endocrine signals could affect patterns of reproductive senescence. The ZAL2 ${ }^{\mathrm{m}}$ supergene encompasses multiple hormone receptors, including estrogen receptor 1 (ESR1), serotonin receptor $1 \mathrm{~B}$ and $1 \mathrm{E}$ (HTR1B and $1 \mathrm{E})$, and the follicle-stimulating hormone receptor (FSHR; Tuttle et al. 2016). Polymorphism in the ESR1 gene alters receptor expression in the brain, affecting morph-specific behaviors (Horton et al. 2014; Maney et al. 2015). Receptor function could also have pleiotropic effects on senescence, for example, by affecting maintenance of immune and reproductive function.
However, rates of reproductive senescence were not consistently associated with morph across the sexes. Rather, in contrast to males, tan females showed higher rates of reproductive senescence than white females. Terminal effects were also more pronounced in white males but tan females. Costs of aggressive behaviors may be mitigated in white females if they engage in these behaviors only during a brief period before nesting commences (Arcese et al. 1988; Pavlova et al. 2007). Nonetheless, the inconsistent pattern across the sexes argues against a strong connection between costs of reproduction and traits associated with the ZAL2 ${ }^{\mathrm{m}}$ supergene. Indeed, neither white males nor white females showed shorter life spans than tan counterparts, with white males instead showing the highest life expectancies. However, senescence in different systems may or may not proceed in parallel (Nussey et al. 2013). Thus, white males but not white females could experience high physiological costs that affect their reproductive system (e.g., spermatogenesis) but not survivorship (e.g., immunity).

Table 3: Binomial generalized linear mixed-effects models predicting paternity retention from age and morph in dimorphic whitethroated sparrow males (A), more polygamous and aggressive white males (B), and more paternal tan males $(\mathrm{C})$

\begin{tabular}{|c|c|c|c|}
\hline A. Males & Estimate $(\beta \pm \mathrm{SE})$ & $Z$ & $P>|Z|$ \\
\hline Intercept & $3.596 \pm .255$ & 14.122 & $<.001$ \\
\hline Age & $.012 \pm .293$ & .042 & .966 \\
\hline Morph $^{\mathrm{a}}$ & $-1.392 \pm .255$ & -5.466 & $<.001$ \\
\hline Age $\times$ morph $^{\mathrm{a}}$ & $-.741 \pm .293$ & -2.524 & .011 \\
\hline Random effects & Variance & SD & $N$ \\
\hline Observation & 6.950 & 2.636 & 403 \\
\hline Individual & .290 & .538 & 208 \\
\hline Year & $<.001$ & $<.001$ & 18 \\
\hline B. White males & Estimate $(\beta \pm \mathrm{SE})$ & $Z$ & $P>|Z|$ \\
\hline Intercept & $1.723 \pm .184$ & 9.378 & $<.001$ \\
\hline Age & $-.615 \pm .182$ & -3.389 & $<.001$ \\
\hline Random effects & Variance & SD & $N$ \\
\hline Observation & 3.324 & 1.823 & 214 \\
\hline Individual & .268 & .517 & 106 \\
\hline Year & $<.001$ & $<.001$ & 17 \\
\hline C. Tan males & Estimate $(\beta \pm \mathrm{SE})$ & $Z$ & $P>|Z|$ \\
\hline Intercept & $6.237 \pm .696$ & 8.964 & $<.001$ \\
\hline Age & $.710 \pm .746$ & .952 & .341 \\
\hline Random effects & Variance & $\mathrm{SD}$ & $N$ \\
\hline Observation & 15.317 & 3.913 & 189 \\
\hline Individual & 2.773 & 1.665 & 102 \\
\hline Year & $<.001$ & .006 & 18 \\
\hline
\end{tabular}

${ }^{a}$ White relative to tan morph. 

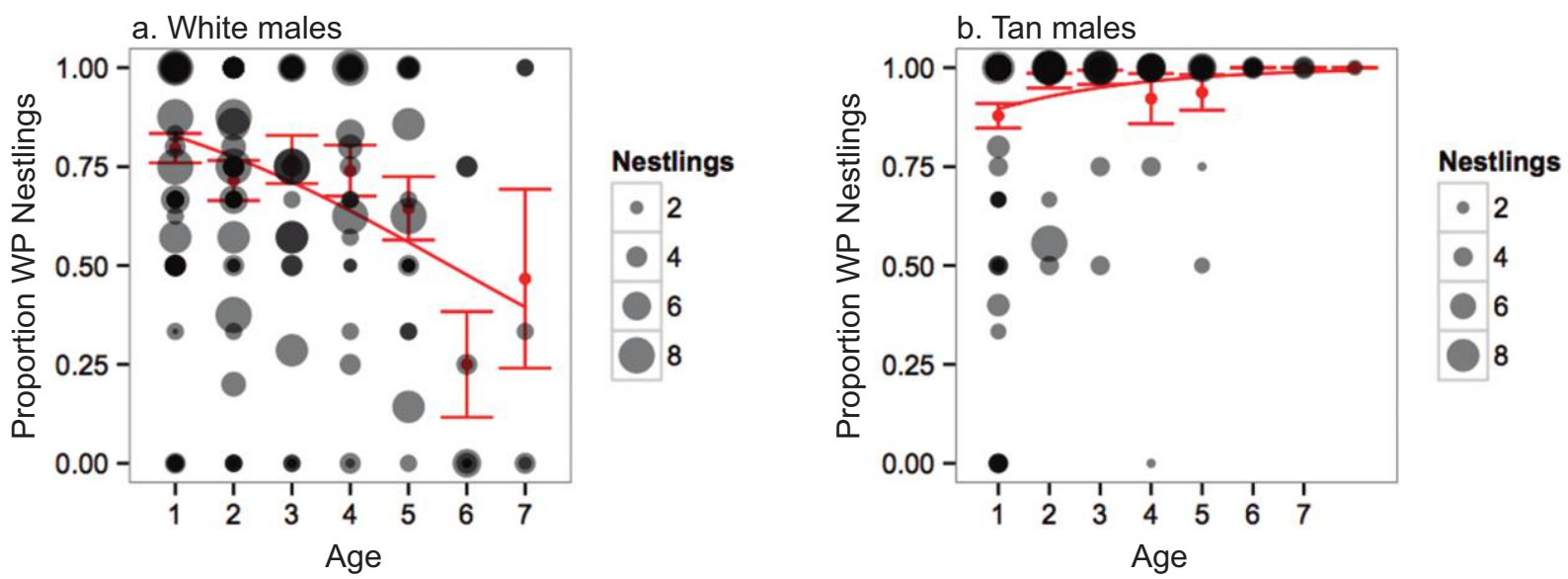

Figure 2: Relationship between paternity retention (proportion of within-pair [WP] nestlings) and age in white male (a) and tan male (b) white-throated sparrows. White males exhibit high rates of extrapair paternity relative to more paternal tan males. Red dots are mean proportions $\pm \mathrm{SE}$ within age groups. Black dots are proportions within nests and are scaled to the number of nestlings in broods. Plots use raw data, and red lines are binomial functions.

Alternatively, rather than reflecting differences in costs of reproduction and rates of systemic decline, faster reproductive senescence in white relative to tan males could result because the competitive reproductive strategy of white males is difficult to sustain given age-related declines in performance. Aging birds will likely be outcompeted for the best territories, social mates, and paternity (via sperm competition; e.g., Bowers et al. 2015) in white but not necessarily in $\tan$ males. Moreover, senescent declines in testosterone levels occur in many species (Ottinger 1992, 2007; Wilcoxen et al. 2013) and could have a larger detrimental effect on reproductive performance in competitive white males than in paternal tan males. This could in turn drive evolution of faster systemic senescence in white males, due to reduced selection for late-life performance. However, results do not support this outcome since white males exhibit long life spans. Rather, intrasexual competition could impose selection on body condition, favoring genes with positive pleiotropic effects on viability (Graves 2007; Bonduriansky et al. 2008).

Given high costs of parental care, we expected higher reproductive senescence in the tan morph, particularly in females. We did not observe faster reproductive senescence in $\tan$ relative to white males, perhaps because white females and $\tan$ males share parental duties. On the other hand, tan females perform parental care with little paternal support,

\section{a. White females}

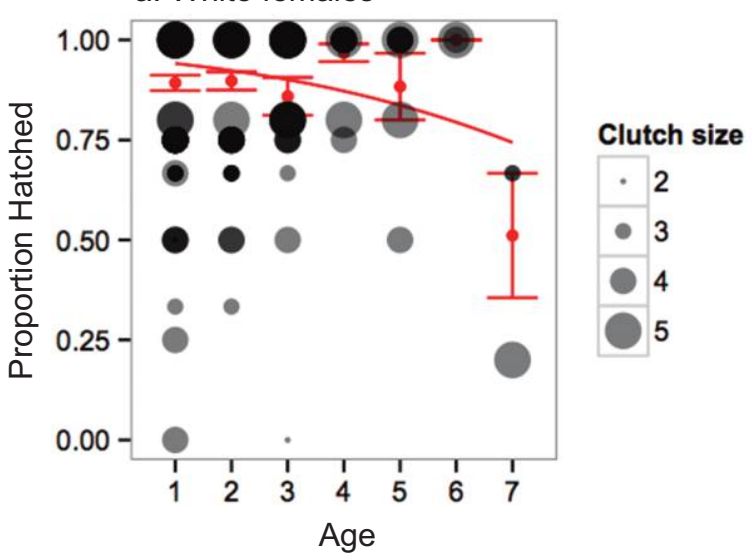

b. Tan females

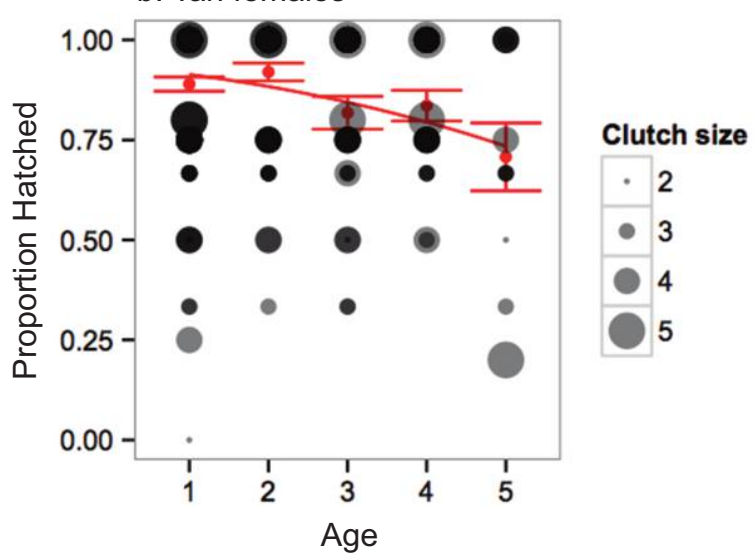

Figure 3: Relationship between hatching success and age for white female $(a)$ and tan female $(b)$ white-throated sparrows. White females are more aggressive and receive more paternal support than tan females. Red dots are mean proportions \pm SE within age groups. Black dots are proportions within nests and are scaled to clutch size. Red lines are binomial functions. 
Table 4: Binomial generalized linear mixed-effects models predicting hatching success from age and morph in dimorphic whitethroated sparrow females (A), more aggressive white females (B), and more parental tan females $(\mathrm{C})$

\begin{tabular}{|c|c|c|c|}
\hline A. Females & Estimate $(\beta \pm \mathrm{SE})$ & $Z$ & $P>|Z|$ \\
\hline Intercept & $2.961 \pm .321$ & 9.237 & $<.001$ \\
\hline Age & $-.189 \pm .155$ & -1.216 & .224 \\
\hline $\mathrm{Age}^{2}$ & $-.154 \pm .074$ & -2.081 & .037 \\
\hline Morph $^{a}$ & $.204 \pm .199$ & 1.025 & .306 \\
\hline Clutch & $-.314 \pm .143$ & -2.193 & .028 \\
\hline Age $\times$ morph $^{\mathrm{a}}$ & $.373 \pm .196$ & 1.900 & .057 \\
\hline Random effects & Variance & $\mathrm{SD}$ & $N$ \\
\hline Nests & .746 & .864 & 434 \\
\hline Individuals & .064 & .254 & 188 \\
\hline Year & .050 & .224 & 16 \\
\hline B. White females & Estimate $(\beta \pm \mathrm{SE})$ & $Z$ & $P>|Z|$ \\
\hline Intercept & $2.813 \pm .258$ & 10.904 & $<.001$ \\
\hline Age & $.185 \pm .240$ & .775 & .439 \\
\hline $\mathrm{Age}^{2}$ & $-.198 \pm .107$ & -1.848 & .064 \\
\hline Random effects & Variance & SD & $N$ \\
\hline Nests & 1.256 & 1.121 & 203 \\
\hline Individuals & $<.001$ & $<.001$ & 89 \\
\hline Year & $<.001$ & $<.001$ & 16 \\
\hline C. Tan females & Estimate $(\beta \pm \mathrm{SE})$ & $Z$ & $P>|Z|$ \\
\hline Intercept & $2.796 \pm .388$ & 7.199 & $<.001$ \\
\hline Age & $-.319 \pm .114$ & -2.809 & .005 \\
\hline Clutch & $-.328 \pm .190$ & -1.720 & .085 \\
\hline Random effects & Variance & $\mathrm{SD}$ & $N$ \\
\hline Nests & .530 & .728 & 231 \\
\hline Individuals & $<.001$ & $<.001$ & 101 \\
\hline Year & .195 & .441 & 16 \\
\hline
\end{tabular}

${ }^{\text {a }}$ White relative to tan morph.

displayed faster reproductive senescence than white females, and had the shortest life span of any sex-morph class. These results suggest that tan females display rapid senescence in condition and survivorship, as well as reproductive success. Indeed, sex-biased parental care predicts sex-biased mortality in Palearctic birds (Owens and Bennett 1994), and single motherhood is associated with stress, disease, and mortality risk in humans (Berkman et al. 2015), demonstrating substantial costs of unsupported parental effort. Conversely, parental support may lower costs of reproduction and rates of reproductive senescence. For instance, cooperative breeding lowers oxidative costs of reproduction in sparrow weavers (Plocepasser mahali; Cram et al. 2015).

In addition to lowering reproductive costs, the cooperative parental system of $\mathrm{T} \times \mathrm{W}$ pairs could allow tan males and white females to better sustain reproduction as system-wide senescence advances. The hypothesis that cooperative behavior facilitates maintenance of reproductive performance in aging individuals has rarely been considered, but a study addressing this idea in meercats (Suricata suricatta) yielded null results (Sharp and Clutton-Brock 2010). In females, results regarding hatching success might seem unlikely to have arisen through this second pathway, because little paternal investment occurs prior to hatching. However, early in the season, tan males could buffer white females from reproductive stress through mate guarding, which can protect females from sexual harassment (Lovell-Mansbridge and Birkhead 1998) and increase foraging efficiency (Fedy and Martin 2009).

Tan males and white females also achieved higher lifetime reproductive success than white males and tan females, with $\tan$ females having the lowest lifetime success. The fitness of white males is underestimated due to incomplete paternity assignment. Nonetheless, these results again suggest that the more cooperative parental system yields higher fitness, at least for females, with disassortative mating maintaining the polymorphism. However, fitness differences between pair types might also vary geographically.

Differences in detectability or dispersion between sexmorph classes could bias our analysis of life span. However, meticulous population monitoring makes it unlikely that breeding individuals go undetected. Moreover, long-term field observations suggest that males of both morphs display high site fidelity and return repeatedly to the same territory in subsequent years. Females switch territories more often than males (which may in part explain slightly lower recapture estimates in females) but with no evidence of a morph bias. Also consistent with the current interpretation, a recent analysis of actuarial senescence using long-term mark-recapture data shows an age-dependent increase in mortality that is

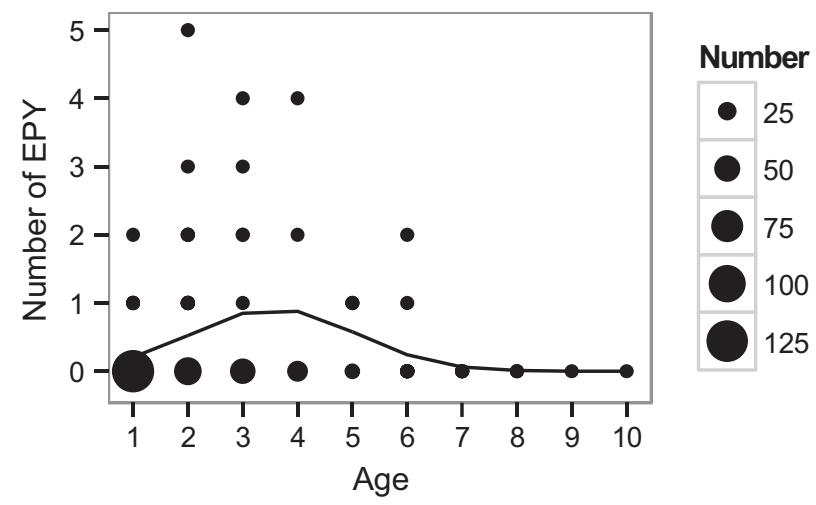

Figure 4: Relationship between number of extrapair young (EPY) and age in white morph males of the dimorphic white-throated sparrow. The black line represents predicted values from the zero-inflated Poisson model. Dots represent the number of EPY per male and are scaled to the number of observations. 
most pronounced in tan females and least pronounced in white males, but with no baseline difference in resighting probability between sex-morph classes (M. L. Grunst et al., unpublished manuscript). Importantly, even if sex, morph, or age-dependent dispersal does occur in the white-throated sparrow, this would likely not bias our analysis of age-dependent reproductive success (trajectories shown in fig. $1 a$ ), which suggest morph differences in reproductive senescence.

Overall, our study suggests that more competitive and less cooperative or supported reproductive strategies are associated with faster reproductive senescence. Results regarding longevity differences between the morphs do not support high self-maintenance costs of intrasexual competition but rather suggest high costs of unsupported parental care. Gaining further insight into why the sex-morph classes display distinct patterns of reproductive senescence will require quantifying age-related changes in physiology, body condition, and behavior. For instance, it will be informative to assess age-related changes in endocrine signaling. These data will allow us to better disentangle whether certain sex-morph classes display faster reproductive senescence due to physiological trade-offs that drive declines in key functions or due to the difficulty of succeeding in highly competitive (white males) or unsupported (tan females) reproductive behaviors as aging advances. Of course, these two processes are also likely to interact, on both ecological and evolutionary time frames.

Data availability: data are deposited to the Dryad Digital Repository: http://dx.doi.org/10.5061/dryad.vj5pn (Grunst et al. 2017).

\section{Acknowledgments}

We acknowledge the white-throated sparrow field crews, Cranberry Lake Biological Station, the Center for Genomic Advocacy at Indiana State University, the Tuttle and Gonser labs, and C. A. T. Gonser. Funding sources included the School of Graduate and Professional Studies at Indiana State University, National Science Foundation grant DUE-0934648, and National Institutes of Health grant 1R01GM084229 (to E.M.T. and R.A.G.). All research reported here was in compliance with the current laws of New York state, the state of Indiana, and the US federal government. Indiana State University's Institutional Animal Care and Use Committee approved all methods (protocols 562158-1 and 562192-1).

\section{Literature Cited}

Alonso-Alvarez, C., S. Bertrand, B. Faivre, O. Chastel, and G. Sorci. 2007. Testosterone and oxidative stress: an oxidation handicap hypothesis. Proceedings of the Roval Societv B 274:819-825.

Arcese, P., P. K. Stoddard, and S. M. Hierbert. 1988. The form and function of song in female song sparrows. Condor 90:44-50.
Bates, D., M. Maechler, and B. Bolker. 2012. lme4: linear mixed-effects models using S4 classes. R package version 0.999999-0. http://CRAN .R-project.org/package $=$ lme4 .

Beirne, C., R. Delahay, and A. Young. 2015. Sex differences in senescence: the role of intra-sexual competition in early adulthood. Proceedings of the Roval Society B 282:20151086.

Berkman, L. F., Y. Zheng, M. M. Glymour, M. Avendano, A. BörschSupan, and E. L. Sabbath. 2015. Mothering alone: cross-national comparisons of later-life disability and health among women who were single mothers. Lournal of Epidemiology and Community Health 69:865-872.

Bolker, B. M., M. E. Brooks, C. J. Clark, S. W. Geange, J. R. Poulsen, H. H. Stevens, and J. S. White. 2009. Generalized linear mixed models: a practical guide for ecology and evolution. Trends in Ecology and Evolution 24:127-135.

Bonduriansky, R., A. Maklakov, F. Zajitschek, and R. Brooks. 2008. Sexual selection, sexual conflict and the evolution of ageing and life span. Functional Ecology 22:443-453.

Boonekamp, J. J., M. Salomons, S. Bouwhuis, C. Dijkstra, and S. Verhulst. 2014. Reproductive effort accelerates actuarial senescence in wild birds: an experimental study. Ecology Letters 17:599-605.

Bouwhuis, S., R. Choquet, B. C. Sheldon, and S. Verhulst. 2012. The forms and fitness cost of senescence: age-specific recapture, survival, reproduction and reproductive value in a wild bird population. American Naturalist 179:E15-E27.

Bouwhuis, S., B. C. Sheldon, S. Verhulst, and A. Charmantier. 2009. Great tits growing old: selective disappearance and the partitioning of senescence to stages within the breeding cycle. Proceedings of the Roval Society B 276:2769-2777.

Bowers, E. K., A. M. Forsman, B. S. Masters, B. G. P. Johnson, L. S. Johnson, S. K. Sakaluk, and C. F. Thompson. 2015. Increased extrapair paternity in broods of aging males and enhanced recruitment of extra-pair young in a migratory bird. Evolution 69:2533-2541.

Briga, M., and S. Verhulst. 2015. What can long-lived mutants tell us about mechanisms causing aging and lifespan variation in natural environments? Experimental Gerontology 71:21-26.

Clutton-Brock, T. H., and K. Isvaran. 2007. Sex differences in ageing in natural populations of vertebrates. Proceedings of the Roval Societv B 274:3097-3104.

Cram, D. L., J. D. Blount, and A. J. Young. 2015. The oxidative costs of reproduction are group-size dependent in a wild cooperative breeder. Proceedings of the Roval Societv B 282:20152031.

Dawson, R., H. Gibbs, K. Hobson, and S. Yezerinac. 1997. Isolation of microsatellite DNA markers from a passerine bird, Dendroica petechia (the yellow warbler), and their use in population studies. Heredity 79:506-514.

Falls, J. B., and J. G. Kopachena. 2010. White-throated sparrow (Zonotrichia albicollis). In A. Poole, ed. The Birds of North America Online. Cornell Lab of Ornithology, Ithaca, NY.

Fedy, B. C., and T. E. Martin. 2009. Male song birds provide indirect parental care by guarding females during incubation. Behavioral Ecology 20:1034-1038.

Folstad, I., and A. J. Karter. 1992. Parasites, bright males, and the immunocompetence handicap hypothesis. American Naturalist 139: 603-622.

Formica, V. A., and E. M. Tuttle. 2009. Examining the social landscapes of alternative reproductive strategies. Lournal of Evolutionary Biology 22:2395-2408.

Forslund, P., and T. Pärt. 1995. Age and reproduction in birds-hypotheses and tests. Trends in Ecology and Evolution 10:374-378. 
Forstmeier, W., and H. Schielzeth. 2011. Cryptic multiple hypotheses testing in linear models: overestimated effect sizes and the winner's curse. Behavioral Ecology and Sociobiology 65:47-55.

Graves, B. M. 2007. Sexual selection effects on the evolution of senescence. Evolutionary Ecology 21:663-668.

Griffiths, R., M. C. Double, K. Orr, and R. J. G. Dawson. 1998. A DNA test to sex most birds. Molecular Ecology 7:1071-1075.

Grunst, A., M. Grunst, V. Formica, M. Korody, A. Betuel, M. BarceloSerra, S. Ford, R. Gonser, and E. Tuttle. 2017. Data from: Morphspecific patterns of reproductive senescence: connections to discrete reproductive strategies. American Naturalist, Dryad Digital Repository, http://dx.doi.org/10.5061/dryad.vj5pn.

Harrison, X. A. 2014. Using observation-level random-effects to model overdispersion in count data in ecology and evolution. PeerI 2:e616.

Horton, B. M., and R. L. Holberton. 2010. Morph-specific variation in baseline corticosterone and the adrenocortical response in breeding white-throated sparrows (Zonotrichia albicollis). Auk 127:540548.

Horton, B. M., W. H. Hudson, E. A. Ortlund, S. Shirk, J. W. Thomas, E. R. Young, W. M. Zinzow-Kramer, and D. L. Maney. 2014. Estrogen receptor $\alpha$ polymorphism in a species with alternative behavioral phenotypes. Proceedings of the National Academv of Sciences of the USA 111:1443-1448.

Jeffery, K. J., L. F. Keller, P. Arcese, and M. W. Bruford. 2001. The development of microsatellite loci in the song sparrow, Melospiza melodia, and genotyping errors associated with good quality DNA. Molecular Ecology Notes 1:11-13.

Kirkwood, T. B. L. 1977. Evolution of ageing. Nature 270:301-304. Knapton, R. W., and J. B. Falls. 1983. Differences in parental contribution among pair types in the polymorphic white-throated sparrow. Canadian Journal of Zoology 61:1288-1292.

Kopachena, J. G., and J. B. Falls. 1993a. Aggressive performance as a behavioral correlate of plumage polymorphism in the whitethroated sparrow (Zonotrichia albicollis). Behaviour 124:249-266. . 1993b. Post-fledging parental care in the white-throated sparrow (Zonotrichia albicollis). Canadian Journal of Zoology 71:227-232.

. $1993 c$. Re-evaluation of morph-specific variations in parental behavior of the white-throated sparrow. Wilson Bulletin 105: 48-59.

Lemaitre, J. F., and J.-M. Gaillard. 2013. Male survival patterns do not depend on male allocation to sexual competition in large herbivores. Behavioral Ecology 24:421-428.

Lemaître, J. F., J.-M. Gaillard, J. M. Pemberton, T. H. Clutton-Brock, and D. H. Nussey. 2014. Early life expenditure in sexual competition is associated with increased reproductive senescence in male red deer. Proceedings of the Roval Society B 281:20140792.

Liker, A., and T. Székely. 2005. Mortality costs of sexual selection and parental care in natural populations of birds. Evolution 59:890-897.

Longmire, J. L., G. F. Gee, O. L. Handenkipf, and G. A. Mark. 1992. Establishing paternity in whooping cranes, Gus americana, by DNA analysis. Auk 109:522-529.

Lovell-Mansbridge, C., and T. R. Birkhead. 1998. Do female pigeons trade pair copulations for protection? Animal Behaviour 56:235-241.

Lowther, J. K. 1961. Polymorphism in the white-throated sparrow, Zonotrichia albicollis (Gmelin). Canadian Journal of Zoology 39: 281-292.

Maney, D. L., K. L. Erwin, and C. T. Goode. 2005. Neuroendocrine correlates of behavioral polymorphism in white-throated sparrows. Hormones and Behavior 48:196-206.
Maney, D. L., B. M. Horton, and W. M. Zinzow-Kramer. 2015. Estrogen receptor alpha as a mediator of life-history tradeoffs. Integrative and Comparative Biology 55:323-331.

Martin, K. 1995. Patterns and mechanisms for age-dependent reproduction and survival in birds. American Zoologist 35:340-348.

Michopoulos, V., D. L. Maney, C. B. Morehouse, and J. W. Thomas. 2007. A genotyping assay to determine plumage morph in the white-throated sparrow (Zonotrichia albicollis). Auk 124:13301335.

Mills, S. C., A. Grapputo, I. Jokinen, E. Koskela, T. Mappes, T. A. Oksanen, and T. Poikonen. 2009. Testosterone-mediated effects on fitness-related phenotypic traits and fitness. American Naturalist 173:475-487.

Møller, A. P., T. A. Mousseau, G. Rudolfsen, J. Balbontin, A. Marzal, I. Hermosell, and F. De Lope. 2009. Senescent sperm performance in old male birds. Journal of Evolutionary Biology 22:334-344.

Monaghan, P., A. Charmantier, D. H. Nussey, and R. E. Ricklefs. 2008. The evolutionary ecology of senescence. Functional Ecology 22:371-378.

Mougeot, F., J. R. Irvine, L. Seivwright, S. M. Redpath, and S. Piertney. 2004. Testosterone, immunocompetence, and honest sexual signaling in male red grouse. Behavioral Ecology 15:930937.

Noguera, J. C., R. Dean, C. Isaksson, A. Velando, and T. Pizarri. 2012. Age-specific oxidative status and the expression of pre- and postcopulatory sexually selected traits in male jungle fowl, Gallus gallus. Ecology and Evolution 2:2155-2167.

Nussey, D. H., T. Coulson, M. Festa-Bianchet, and J.-M. Gaillard. 2008. Measuring senescence in wild animal populations: towards a longitudinal approach. Functional Ecology 22:393-406.

Nussey, D. H., H. Froy, J. F. J. Lemaitre, J.-M. Gaillard, and S. N. Austad. 2013. Senescence in natural populations of animals: widespread evidence and its implications for bio-gerontology. Ageing Research Review 12:214-225.

Nussey, D. H., L. E. B. Kruuk, A. Donald, M. Fowlie, and T. H. Clutton-Brock. 2006. The rate of senescence in maternal performance increases with early-life fecundity in red deer. Ecology Letters 9:1342-1350.

Nussey, D. H., L. E. B. Kruuk, A. Morris, M. N. Clements, J. M. Pemberton, and T. H. Clutton-Brock. 2009. Inter- and intrasexual variation in aging patterns across reproductive traits in a wild red deer population. American Naturalist 174:342-357.

Ottinger, M. A. 1992. Altered neuroendocrine mechanisms during reproductive aging. Poultry Science Review 4:235-248.

. 2007. Neuroendocrine aging in birds: comparing lifespan differences and conserved mechanisms. Ageing Research Review 6:46-53.

Owens, I. P. F., and P. M. Bennett. 1994. Mortality costs of parental care and sexual dimorphism in birds. Proceedings of the Roval Societv B 257:1-8.

Pavlova, D. Z., R. Pinxten, V. M. Darras, and M. Eens. 2007. Effects of nest boxes and males on female song activity in the European starling: an experimental study. Behaviour 144:1255-1271.

Peron, G., O. Giminez, A. Charmantier, J.-M. Gaillard, and P. A. Crochet. 2010. Age at the onset of senescence in birds and mammals is predicted by early-life performance. Proceedings of the Roval Societv B 277:2849-2856.

Petren, K. 1998. Microsatellite primers from Geospiza fortis and crossspecies amplification in Darwin's finches. Molecular Ecology 7:17711788. 
Piper, W. H., and R. H. Wiley. 1989. Distinguishing morphs of the whitethroated sparrow in basic plumage. Journal of Field Ornithology 60: 73-83.

Poesel, A., H. L. Gibbs, and D. A. Nelson. 2009. Twenty-one novel microsatellite DNA loci isolated from the Puget Sound whitecrowned sparrow, Zonotrichia leucophrys pugetensis. Molecular Ecology Resources 9:795-798.

Préault, M., O. Chastel, F. Cézilly, and B. Faivre. 2005. Male bill colour and age are associated with parental abilities and breeding performance in blackbirds. Behavioral Ecology and Sociobiology 58:497-505.

Preston, B. T., M. Saint Jalme, Y. Hingrat, F. Lacroix, and G. Sorci. 2011. Sexually extravagant males age more rapidly. Ecology Letters 14 1017-1024.

2015. The sperm of aging male bustards retards their offspring's development. Nature Communications 6:6146.

R Development Core Team. 2012. R: a language and environment for statistical computing. R Foundation for Statistical Computing, Vienna. http://www.R-project.org.

Reichert, S., A. Stier, Z. Sandrine, M. Arrivé, P. Bize, S. Massemin, and F. Criscuolo. 2014. Increased brood size leads to persistent eroded telomeres. Frontiers in Ecology and Evolution 2:9.

Rivera-Gutierrez, H. F., R. Pinxten, and M. Eens. 2012. Tuning and fading voices in songbirds: age-dependent changes in two acoustic traits across the life span. Animal Behaviour 83:1279-1283.

Romanov, M. N., E. M. Tuttle, M. L. Houck, W. S. Modi, L. G. Chemnick, M. L. Korody, E. M. S. Mork, et al. 2009. The value of avian genomics to the conservation of wildlife. BMC Genomics 10:S10.

Schielzeth, H. 2010. Simple means to improve the interpretability of regression coefficients. Methods in Ecologv and Evolution 1:103-113.

Sharp, S. P., and T. H. Clutton-Brock. 2010. Reproductive senescence in a cooperatively breeding mammal. Iournal of Animal Ecology 79: 176-183.

Swett, M. B., and C. W. Breuner. 2009. Plasma testosterone correlates with morph type across breeding substages in male white-throated sparrows. Physiological and Biochemical Zoology 82:572-579.

Thorneycroft, H. B. 1966. Chromosomal polymorphism in the whitethroated sparrow, Zonotrichia albicollis. Science 154:1571-1572.
Tidiére, M., J.-M. Gaillard, D. W. H. Müller, L. B. Lackey, O. Gimenez, M. Clauss, and J.-F. Lemaitre. 2015. Does sexual selection shape sex differences in longevity and senescence patterns across vertebrates? a review and new insights from captive ruminants. Evolution 69:31233140 .

Torres, R., and A. Velando. 2007. Male reproductive senescence: the price of immune induced oxidative damage on sexual attractiveness in the blue-footed booby. Journal of Animal Ecology 76:1161-1168.

Tuttle, E. M. 1993. Mate choice and the maintenance of stable polymorphisms in the white-throated sparrow. PhD diss. State University of New York at Albany, Albany.

- 2003. Alternative reproductive strategies in the whitethroated sparrow: behavioral and genetic evidence. Behavioral Ecology 14:425-432.

Tuttle, E. M., A. O. Bergland, M. Korody, M. Brewer, D. Newhouse, P. Minx, M. Stager, et al. 2016. Divergence and functional degradation of a sex chromosome-like supergene. Current Biology 26:344-350.

Velando, A., J. C. Noguera, H. Drummond, and R. Torres. 2011. Senescent males carry premutagenic lesions in sperm. Iournal of Evolutionary Biology 24:693-697.

Vercken, E., M. Massot, B. Sinervo, and J. Clobert. 2007. Colour variation and alternative reproductive strategies in females of the common lizard Lacerta vivipara. Journal for Evolutionary Biology 20: 221-232.

Wilcoxen, T. E., E. S. Bridge, R. K. Boughton, T. P. Hahn, and S. J. Schoech. 2013. Physiology of reproductive senescence in Florida scrub-jays: results from a long-term study and GnRH challenge. General and Comparative Endocrinology 194:168-174.

Williams, G. C. 1957. Pleiotropy, natural selection and the evolution of senescence. Evolution 11:398-411.

Zhang, H., O. Vedder, P. H. Becker, and S. Bouwhuis. 2015. Agedependent trait variation: the relative contribution of within-individual change, selective appearance and disappearance in a long-lived seabird. Journal of Animal Ecology 84:797-807.

Associate Editor: Jeff Leips Editor: Alice A. Winn

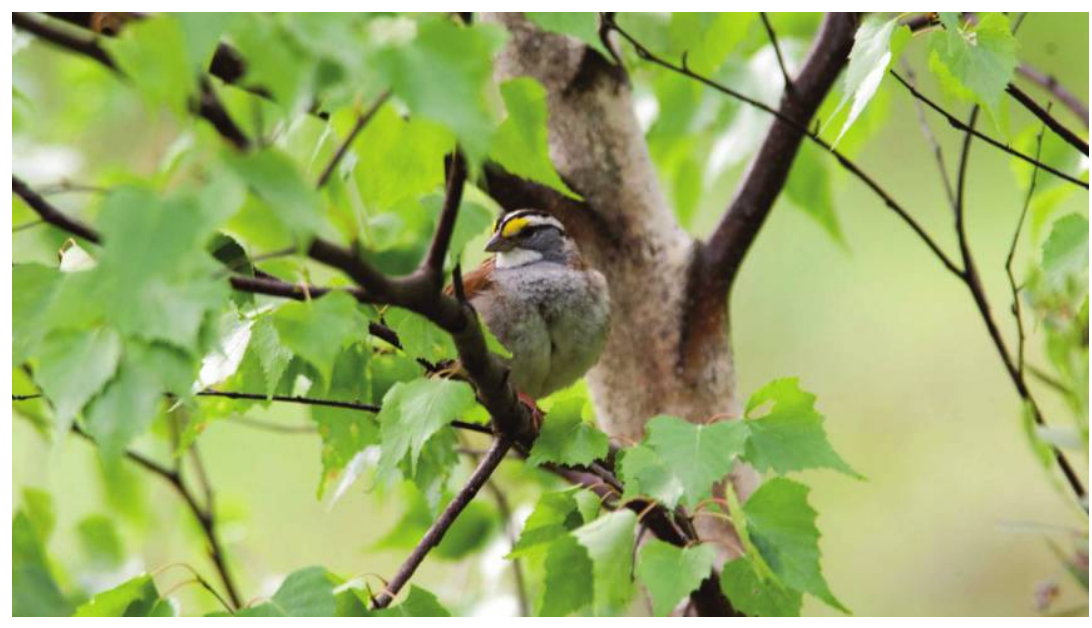

Female white-striped sparrow (Zonotrichia albicollis) perched showing brood patch. Photo credit: Indiana State University Photo Services. 